\title{
Identification of risk factors for non-fatal child injury in a rural area: Keokuk County Rural Health Study
}

\author{
D L Nordstrom, C Zwerling, A M Stromquist, L F Burmeister, J A Merchant
}

Injury Prevention 2003;9:235-240

\begin{abstract}
Objective: To identify risk factors for non-fatal injury among rural children.
Design: Cross sectional health interview survey, 1994-98.

Setting: A rural lowa county, not adjacent to a metropolitan area.

Subjects: Stratified, random sample of households, including all resident children and adults.

Main outcome measures: Injury episodes in the past 12 months among children aged 0-17 years and the parental and child characteristics associated with these episodes.

Results: Of the 621 children in participating households, 137 or $22.1 \%$ were injured during the past 12 months. Children age 5-17 on a sports team were 1.88 times $(95 \%$ confidence interval (CI) 1.07 to 3.31 ) more likely than other children to be injured. Children age 12-17 who binge drink were 3.50 times $(95 \% \mathrm{Cl} 1.31$ to 9.50$)$ more likely than other children to be injured. Compared with children not on sports teams, girls on teams were 2.26 times $(95 \% \mathrm{Cl} 1.02$ to 5.13$)$ more likely while boys on teams were 1.60 times $(95 \% \mathrm{Cl} 0.71$ to 3.68$)$ more likely to have an injury episode. Compared with children who did not binge drink, girls binge drinking were 8.11 times $(95 \% \mathrm{Cl} 1.52$ to 43.33$)$ more likely while boys binge drinking were 2.19 times $(95 \% \mathrm{Cl} 0.70$ to 6.84$)$ more likely to have an injury episode.

Conclusions: Local studies such as this can provide useful clues regarding the etiology of injury. Some known and some new potential risk factors including behavioral aspects for childhood non-fatal injury in a very rural area were investigated. It is planned to address these cross sectional findings in future longitudinal follow up of this population.
\end{abstract}

A though the death rate among children and teenagers in the United States fell $7.5 \%$ in the past decade, ${ }^{1}$ unintentional injury is still the leading cause of death. ${ }^{2}$ Data on non-fatal injury among US children are more limited. Medically attended injuries occur in $25 \%$ of children annually. ${ }^{3}$ The most recent national estimates of medically attended episodes of injury among children are from the 1997 National Health Interview Survey (NHIS). ${ }^{4}$ In addition, the National Electronic Injury Surveillance System provides age specific national estimates of non-fatal injuries treated in US hospital emergency departments. ${ }^{5}$ However, both of these data systems lack details on the mechanism and circumstances of injury and for states and smaller areas. Our local study is able to provide more specific, thorough information on childhood injury, especially for a rural population. Using data from a recent health survey, ${ }^{6}$ we were able to investigate a broad range of potential risk factors for childhood injury that encompasses social, psychological, biological, and behavioral characteristics of children and their families.

\section{METHODS}

\section{Study population}

The study county (1990 population 11624 with 20.1 persons per square mile) is among the nation's "most rural"- that is, totally rural and not adjacent to a metropolitan areaaccording to a federal scheme. ${ }^{7}$ It has five doctors and a 33 bed general hospital with ambulance service.

From a compiled list of all county households, we sampled households randomly stratified by residence-farm, town, and other rural (non-farm and non-town)-with oversampling of farm and non-farm, non-town households to yield more information on certain agricultural exposures for other analyses (for more details on study methods see Merchant et $\left.a l^{6}\right)$.
Of the 2497 households verified as eligible during the enrollment period, $1052(42.1 \%)$ provided at least one adult who agreed to be interviewed. Another 624 (25.0\%) indicated they might participate in a future round of the survey (see full description in Merchant et $a l^{6}$ ). Also, 781 households (31.3\%) refused participation now and in the future.

To assess bias, we contacted 200 households chosen randomly from those that had refused participation. Participating and non-participating households were similar by adult member's age and marital status, presence of children, and presence of farmers. Households differed by proportion with a high school graduate $(92.9 \%$ of participants $v 88.5 \%$ of refusers, $\chi^{2}$ test, $\mathrm{p}=0.033$ ).

\section{Data collection}

The University of Iowa institutional review board approved the study protocol and data collection instruments. We invited all adults and youths age 12-17 years in study households to be interviewed. Trained staff personally interviewed study participants during 1994-98 at the study office. Each adult interview lasted 60-90 minutes. Part of one adult interview per household covered children aged 0-17 years. We also environmentally assessed every home and farm.

\section{Outcome definition}

We asked one adult per household to recall the "accidents and injuries" each child aged 0-17 had during the past 12 months.

Abbreviations: CAGE, Cut down, Annoyed, Guilty, Eye opener (questionnaire); CES-D scale, Center for Epidemiologic Studies Depression Scale; CI, confidence interval; ICD-9-CM, International Classification of Diseases, 9th revision, clinical modification; NHIS National Health Interview Survey 
Table 1 Classification by cause, place, and type of most recent injury in past 12 months among 621 rural children aged 0-17, based on parental interview in 1994-98

\begin{tabular}{|c|c|c|c|c|c|c|c|c|}
\hline Cause & No & $\%$ & Place & No & $\%$ & Type & No & $\%$ \\
\hline Struck by/against & 35 & 25.5 & Recreation and sport & 54 & 39.4 & Sprain or strain & 37 & 27.0 \\
\hline Fall & 34 & 24.8 & Home & 39 & 28.5 & Open wound or laceration & 36 & 26.3 \\
\hline Overexertion & 18 & 13.1 & Farm & 7 & 5.1 & Neck, trunk, upper limb fracture & 19 & 13.9 \\
\hline Cut/pierce & 15 & 10.9 & Street and highway & 5 & 3.6 & Contusion: intact skin & 15 & 10.9 \\
\hline Transport, other & 8 & 5.8 & Public building & 4 & 2.9 & Superficial injury & 6 & 4.4 \\
\hline Motor vehicle & 6 & 4.4 & Industry & 1 & 0.7 & Lower limb fracture & 5 & 3.6 \\
\hline Bicycle & 4 & 2.9 & Other place & 4 & 2.9 & Dislocation & 5 & 3.6 \\
\hline Animal bites & 4 & 2.9 & Unknown place & 23 & 16.8 & Crushing injury & 3 & 2.2 \\
\hline Foreign body & 4 & 2.9 & & & & Skull fracture & 2 & 1.5 \\
\hline Caught & 2 & 1.5 & & & & Toxic effect: non-medical & 2 & 1.5 \\
\hline Other cause & 6 & 4.4 & & & & Other type & 7 & 5.1 \\
\hline Unknown cause & 1 & 0.7 & & & & & & \\
\hline Total & 137 & 99.8 & Total & 137 & 100.0 & Total & 137 & 100.0 \\
\hline
\end{tabular}

Note: for details on the contents of the above lists, see "statistical methods" section. Excludes "mine and quarry" because no injuries occurred in that

place.

Injuries must have restricted normal activities for at least four hours, resulted in blacking out or losing awareness or memory for any length of time, or required professional care. We asked detailed questions about the most recent injury episode, if any, for each child. We defined each injury as "consequential"having at least one bed day or lost school day, hospitalization, or surgery ${ }^{8}$ - or "minor".

In 1999, after all interviews were completed, a study employee trained by a certified medical records professional assigned International Classification of Diseases, 9th revision, clinical modification (ICD-9-CM) diagnosis, cause, and place of occurrence codes to all injuries. To select codes, he read the parent's narrative answers to questions on description of injury, what the child was doing at time of injury, how the injury happened, what body parts were injured, and what injury diagnosis resulted.

All cases were assigned an $\mathrm{N}$ code in the range 800-999, the injury and poisoning diagnosis chapter of ICD-9-CM, or an E code in the range 800-999, the supplementary classification of external causes of injury and poisoning of ICD-9-CM. We excluded cases of adverse effect of health care in accord with current practice in the US. ${ }^{9}$

\section{Risk factor definitions}

Prior research provided a list of risk factors for child injury that have been identified or examined..$^{10-15}$ Guided by these and our own experience, we chose a limited set of potential risk factors that includes social, psychological, biological, and behavioral characteristics of children and their families. Injury mechanism specific risk factors were excluded.

All study participants assigned their residence to farm, town, or other rural (non-farm and non-town) place. We asked one adult per household each child's age, sex, current grade in school, sports team(s) if age 5-11, current emotional health, current behavior problems, and current impairments. Children aged 12-17 provided their sports team and alcohol use information, and children aged 8-17 provided their medications information during a family medical screening. We asked the adult, usually the mother, who provided information on the child's injury, her current marital status and a rating of fear for children's safety around her spouse. For all adults in each household, we assessed lifetime alcohol abuse or dependence, current alcohol binge drinking, lifetime antisocial personality, and current depression symptoms.

Survey alcohol questions preceded the injury questions. First, we asked all adults the four questions of the CAGE (Cut down, Annoyed, Guilty, Eye opener) questionnaire. ${ }^{16}$ Adults who answered two or more of these questions "yes" were classified as having lifetime prevalence of alcohol abuse or dependence (sensitivity $74 \%$, specificity $91 \%{ }^{17}$ ). Second, we asked all adults and youth aged 12-17, "On about how many days did you have five or more drinks of beer, wine or liquor on the same occasion during the past 30 days?" This question has been asked by the Centers for Disease Control and Prevention to measure current episodic heavy drinking, also called "binge drinking". We classified any adult or youth who answered one or more days to this question as having current binge drinking.

To identify lifetime prevalence of antisocial personality in adults, we used 10 questions about behavior since age 15 from the National Comorbidity Survey. ${ }^{18}$ As per the Diagnostic and Statistical Manual of Mental Disorders (3rd edition, revised), four or more "yes" responses indicate positive for lifetime prevalence of antisocial personality.

To assess depression symptoms in adults, we used a shorter form $^{19}$ of the Center for Epidemiologic Studies Depression Scale (CES-D scale). ${ }^{20}$ We chose a cutpoint for high frequency of depression symptoms representing the 80th percentile of our participants' scores, which reflects the upper quintile of scores for patient populations on which the National Institute of Mental Health ${ }^{21}$ validated the original CES-D instrument.

\section{Statistical methods}

To sort the episodes into groups for intent and E code causes of injury, we followed the framework recommended by the Centers for Disease Control and Prevention and the American Public Health Association. ${ }^{22}$ For $\mathrm{N}$ code diagnoses of injury, we followed the classes of the National Center for Health Statistics. ${ }^{23}$ For place of occurrence, we used the list of ICD-9-CM place codes (E849).

We conducted cross sectional descriptive analyses. The unit of analysis was the individual child. Children from 303 households, with 1-7 children each, were analyzed. Twenty three other children from study households are not analyzed here because their forms are missing.

Sample sizes reported in the tables reflect the actual number of subjects in each group. Because of the complex sampling design, we used Software for the Statistical Analysis of Correlated Data (SAS-callable SUDAAN for SAS version 6.12) to estimate crude prevalence odds ratios and associated $95 \%$ confidence intervals. The confidence intervals give a range of values for odds ratios that are compatible with the data in our study. For each analysis, all individuals with nonmissing information on the outcome and exposure variables were included. We repeated the analysis with consequential injury episodes only. 
Table 2 Comparison of child characteristics for 621 injured and non-injured rural children aged $0-17$ in past 12 months, based on parental and child interview in 1994-98

\begin{tabular}{|c|c|c|c|}
\hline & No (\%) injured & No (\%) not injured & Odds ratio $(95 \% \mathrm{Cl})$ \\
\hline $\begin{array}{l}\text { Age in years per parent, in quart } \\
0-5 \\
6-9 \\
10-13 \\
14-17\end{array}$ & $\begin{array}{l}\text { based on poole } \\
24(14.8) \\
26(15.7) \\
32(21.9) \\
55(37.4)\end{array}$ & $\begin{array}{l}\text { for all children } \\
138(85.2) \\
140(84.3) \\
114(78.1) \\
92(62.6)\end{array}$ & $\begin{array}{l}\text { Referent } \\
1.07 \text { (0.56 to } 2.03) \\
1.61 \text { (0.87 to } 3.02) \\
3.44 \text { (1.92 to } 6.17)\end{array}$ \\
\hline $\begin{array}{l}\text { Gender per parent (missing data } \\
\text { Female } \\
\text { Male }\end{array}$ & $\begin{array}{l}r n=1) \\
63(22.0) \\
73(21.9)\end{array}$ & $\begin{array}{l}223(78.0) \\
261(78.1)\end{array}$ & $\begin{array}{l}\text { Referent } \\
0.99(0.66 \text { to } 1.48)\end{array}$ \\
\hline $\begin{array}{l}\text { Residence per parent } \\
\text { Town } \\
\text { Non-farm, non-town } \\
\text { Farm }\end{array}$ & $\begin{array}{l}50(20.2) \\
33(21.4) \\
54(24.5)\end{array}$ & $\begin{array}{l}197(79.8) \\
121(78.6) \\
166(75.4)\end{array}$ & $\begin{array}{l}\text { Referent } \\
1.07(0.64 \text { to } 1.81) \\
1.28(0.81 \text { to } 2.03)\end{array}$ \\
\hline $\begin{array}{l}\text { School grade per parent (missing } \\
\text { Not in school } \\
\text { Preschool or kindergarten } \\
\text { Grade 1-6 } \\
\text { Grade 7-9 } \\
\text { Grade 10-12 }\end{array}$ & $\begin{array}{l}\text { lata for } n=9) \\
17(15.2) \\
13(17.8) \\
43(18.3) \\
30(25.9) \\
33(43.4)\end{array}$ & $\begin{array}{r}95(84.8) \\
60(82.2) \\
192(81.7) \\
86(74.1) \\
43(56.6)\end{array}$ & $\begin{array}{l}\text { Referent } \\
1.21 \text { (0.51 to } 2.86) \\
1.25 \text { (0.65 to } 2.42) \\
1.95 \text { (0.96 to } 3.99) \\
4.29 \text { (2.05 to } 9.05)\end{array}$ \\
\hline $\begin{array}{l}\text { Current emotional health per par } \\
\text { Excellent, very good or good } \\
\text { Fair or poor }\end{array}$ & $\begin{array}{l}+ \text { (missing data fo } \\
129(22.4) \\
6(20.7)\end{array}$ & $\begin{array}{r}448(77.6) \\
23(79.3)\end{array}$ & $\begin{array}{l}\text { Referent } \\
0.91 \quad(0.32 \text { to } 2.41)\end{array}$ \\
\hline $\begin{array}{l}\text { Current number of behavior prob } \\
\text { Some or almost none } \\
\text { A lot or quite a few }\end{array}$ & $\begin{array}{l}\text { ms per parent }(\mathrm{mi} \\
130(22.3) \\
5(20.0)\end{array}$ & $\begin{array}{l}\text { data for } n=13) \\
453(77.7) \\
20(80.0)\end{array}$ & $\begin{array}{l}\text { Referent } \\
0.87(0.28 \text { to } 2.52)\end{array}$ \\
\hline $\begin{array}{l}\text { On any sports team in past } 12 \mathrm{~m} \\
\text { (missing data for } n=185 \text { ) } \\
\text { No } \\
\text { Yes }\end{array}$ & $\begin{array}{l}\text { hs per parent if } \\
21(16.4) \\
83(26.9)\end{array}$ & $\begin{array}{l}11 \text { and per child if a } \\
107(83.6) \\
225(73.0)\end{array}$ & $\begin{array}{l}12-17 \\
\text { Referent } \\
1.88 \text { (1.07 to } 3.31)\end{array}$ \\
\hline $\begin{array}{l}\text { Any impairment or health proble } \\
\text { No } \\
\text { Yes }\end{array}$ & $\begin{array}{l}\text { that limits activitie } \\
119(21.6) \\
14(25.9)\end{array}$ & $\begin{array}{l}\text { Darent (missing data f } \\
431(78.4) \\
40(74.1)\end{array}$ & $\begin{array}{l}\mathrm{n}=17) \\
\text { Referent } \\
1.27(0.63 \text { to } 2.50)\end{array}$ \\
\hline $\begin{array}{l}\text { Any sedatives, tranquilizers, stim } \\
\text { (missing data for } n=300 \text { ) } \\
\text { No } \\
\text { Yes }\end{array}$ & $\begin{array}{l}\text { nts, or analgesic } \\
81(26.6) \\
8(50.0)\end{array}$ & $\begin{array}{l}\text { in past } 12 \text { months } p \\
224(73.4) \\
8(50.0)\end{array}$ & $\begin{array}{l}\text { child if age } 8-17 \\
\text { Referent } \\
2.77(0.87 \text { to } 8.73)\end{array}$ \\
\hline $\begin{array}{l}\text { Binge drinking in past } 30 \text { days } p \\
\text { No } \\
\text { Yes }\end{array}$ & $\begin{array}{l}\text { child if age } 12-1 \\
\qquad 8(30.8) \\
14(60.9)\end{array}$ & $\begin{array}{l}\text { sing data for } n=442) \\
108(69.2) \\
9(39.1)\end{array}$ & $\begin{array}{l}\text { Referent } \\
3.50 \text { (1.31 to } 9.50)\end{array}$ \\
\hline
\end{tabular}

\section{RESULTS}

Of the 621 children for whom an adult completed an interview, 224 were adolescents aged 12-17 and 397 were other children aged $0-11$. One hundred thirty seven $(22.1 \%)$ reportedly had an injury episode during the past 12 months. Of the 137 injured children, $122(89.2 \%)$ were seen by a health professional. About 13\% of all injured children were reported to have had more than one injury episode during the past 12 months.

The most frequent cause of injury was being struck by or striking against objects or persons (table 1), with 35 cases $(25.5 \%)$. Falls ranked second, with 34 cases $(24.8 \%)$. Only six cases $(4.4 \%)$ were injured in motor vehicle crashes. All episodes were unintentional except one assault. Place for recreation and sport, $39.4 \%$, and home, $28.5 \%$, were the most common places of occurrence.

Of the 137 injuries, 37 (27.0\%) were sprains or strains, and $36(26.3 \%)$ were open wounds or lacerations (table 1). Fifty three $(38.7 \%)$ of the injuries had at least one bed day or lost school day, hospitalization, or surgery. The agent of injury was nearly always mechanical energy.

Perhaps the most serious episode was that of a 16 year old boy who required nine days of rest, the most of any reported. While checking farm animal traps, he hit a bump and flipped his all-terrain vehicle. Hospital surgery repaired a broken jaw, teeth, and scapula.

Almost nine tenths of the overexertion injuries, two thirds of the struck by or against injuries, and one third of the fall injuries occurred in recreation and sport places. Seven of the 137 episodes, including five on farms, occurred while the child was working. Despite a sample with $35.4 \%$ farm residents representing $39.4 \%$ of injury episodes (table 2 ), only $5.1 \%$ of episodes occurred on farms (table 1 ).

The frequency of injury episode was about double in children age 5-17 who were on a sports team and about triple in children age 12-17 who binge drank in the 30 days before interview (table 2). As compared with children not on sports teams, girls on teams were 2.26 times ( $95 \%$ confidence interval (CI) 1.02 to 5.13) more likely while boys on teams were 1.60 times ( $95 \%$ CI 0.71 to 3.68 ) more likely to have an injury episode. Compared with children who did not binge drink, binge drinking girls were 8.11 times (95\% CI 1.52 to 43.33 ) more likely while binge drinking boys were 2.19 times (95\% CI: 0.70 to 6.84 ) more likely to have an injury episode. Of the eight team sports assessed, track team members were more likely than non-members to have an injury $\left(54.5 \% v 23.0 \%, \chi^{2}\right.$ test, $p=0.001$ ), and volleyball team members were more likely 
Table 3 Comparison of adult characteristics in households of 621 injured and non-injured rural children aged $0-17$ in past 12 months, per interview of parent and other adults in 1994-98

\begin{tabular}{|c|c|c|c|}
\hline & No (\%) injured & No (\%) not injured & Odds ratio $(95 \% \mathrm{Cl})$ \\
\hline \multicolumn{4}{|c|}{$\begin{array}{l}\text { Presence of spouse or partner currently living in household of adult who reported child demographic } \\
\text { information (missing data for } n=37 \text { ) }\end{array}$} \\
\hline Yes & $120(22.1)$ & $422(77.9)$ & Referent \\
\hline No & $8(19.0)$ & $34(80.9)$ & 0.83 (0.34 to 1. .93 ) \\
\hline \multicolumn{4}{|c|}{$\begin{array}{l}\text { Frequency afraid for the safety of your children during the past } 12 \text { months when you are around your spous } \\
\text { or partner, according to the adult who reported child injury status (missing data for } n=67 \text { ) }\end{array}$} \\
\hline $\begin{array}{l}\text { None of time } \\
\text { All, most or some of time }\end{array}$ & $\begin{array}{r}110(21.4) \\
11(27.5)\end{array}$ & $\begin{array}{r}404(78.6) \\
29(72.5)\end{array}$ & $\begin{array}{l}\text { Referent } \\
1.39(0.63 \text { to } 3.02)\end{array}$ \\
\hline \multicolumn{4}{|c|}{$\begin{array}{l}\text { Lifetime prevalence of alcohol abuse or dependence as determined by a CAGE score of } 2 \text { or more for any } \\
\text { adult living in the child's household (missing data for } n=8 \text { ) }\end{array}$} \\
\hline No & $107(23.8)$ & $342(76.2)$ & Referent \\
\hline Yes & $29(17.7)$ & $135(82.3)$ & 0.69 (0.42 to 1.11 ) \\
\hline \multicolumn{4}{|c|}{ Binge drinking in past 30 days by any adult living in the child's household (missing data for $n=9$ ) } \\
\hline No & $84(22.3)$ & $293(77.7)$ & Referent \\
\hline Yes & $51(21.7)$ & $184(78.3)$ & $0.97(0.64$ to 1.46$)$ \\
\hline \multicolumn{4}{|c|}{ Antisocial personality score of 4 or more by any adult living in the child's household (missing data for $n=6$ ) } \\
\hline No & $125(22.8)$ & $422(77.1)$ & Referent \\
\hline Yes & $11(16.2)$ & $57(83.8)$ & 0.65 (0.31 to 1.33 ) \\
\hline \multicolumn{4}{|c|}{ Depression symptoms during the past week by any adult living in the child's household (missing data for $n=0$} \\
\hline Low & $92(22.4)$ & $318(77.6)$ & Referent \\
\hline High & $44(21.5)$ & $161(78.5)$ & $0.94(0.62$ to 1.45$)$ \\
\hline
\end{tabular}

than non-members to have an injury $\left(50.0 \% v 29.0 \%, \chi^{2}\right.$ test, $\mathrm{p}=0.009$ ).

Children on medication during the past 12 months, usually Tylenol with codeine, apparently had higher injury rates than children not on medications. Injury prevalence did not seem to vary among the three residence strata (table 2 ) nor with any of six adult risk factors (table 3 ).

We also reanalyzed the data using a more narrowly defined outcome measure that included only the 53 injuries with at least one bed day or lost school day, hospitalization, or surgery. This did not substantially change the odds ratios for most of the parent or child characteristics we investigated. However, the association between consequential injury and child fair or poor current emotional health was 1.17 (95\% CI 0.36 to 3.84 ) compared with the odds ratio of 0.91 (95\% CI 0.32 to 2.41 ) that we observed for all 137 injuries. In addition, the consequential injury odds ratio for children with a lot or quite a few behavioral problems was 1.36 (95\% CI 0.40 to 4.65 ) compared with the odds ratio of 0.87 ( $95 \%$ CI 0.28 to 2.52 ) observed when all injuries were included.

\section{DISCUSSION}

Among participants in an extensive rural health survey, overall prevalence of childhood non-fatal injury was found to be higher than that observed in a national survey. Our evaluation of specific risk factors showed that participation in team sports and binge drinking were associated with increased injuries.

\section{Prevalence}

Compared with a rate of 22.1 injuries per 100 children aged $0-17$ in our survey, there were 11.2 injuries per 100 children aged $0-11$ and 17.1 injuries per 100 children aged $12-21$ in the US, according to the 1997 NHIS. ${ }^{4}$ However, many of the potential risk factors assessed in our study were not assessed in the NHIS. In addition, the National Electronic Injury Surveillance System estimated the 2000 US rate of child injury treated in hospital emergency departments, including all types of intention and all places of residence, to be 13.7 at age $0-4,12.1$ at age $5-9,13.4$ at age $10-14$, and 16.9 at age 15-19, per 100 population. ${ }^{5}$

\section{Rural}

Our survey had no urban participants, so we cannot make an internal comparison of rural to urban injury prevalence. In an analysis of injury data for children aged 0-17 from the 1988 NHIS, Overpeck et al found no significant effect of urbanicity of place of residence on the rate of injury. ${ }^{8}$ However, in the 1997-98 National Ambulatory Medical Care Survey, the all types of intent injury visit rate of children age 0-18 to primary care offices was 16.3 per 100 person-years in non-metro places compared with 13.2 per 100 person-years in metro places. ${ }^{24}$ Similarly, annual injury prevalence in Maryland children aged $11-17$ was $65 \%$ in a rural area and $53 \%$ in an urban area. ${ }^{15}$

\section{Alcohol}

Thought to be the most abused drug in America, ${ }^{25}$ alcohol is linked to a wide variety of fatal injuries. ${ }^{26}$ Alcohol may increase the incidence or the severity of injury or both. Two fifths of motor vehicle deaths are alcohol related, ${ }^{27}$ and alcohol impairment contributes to $40 \%$ of residential fire deaths. ${ }^{27}$ Neither motor vehicle nor fire injuries occurred often in our study, and it is likely that the role of alcohol abuse varies by injury mechanism and intent. ${ }^{26}$

While numerous studies of adolescents admitted for trauma care have found alcohol to be an important contributor, ${ }^{14}$ our study shows that alcohol is also a risk factor for injury seen in primary care. We assessed the relation between injury and binge drinking, while other investigators have defined the exposure as either lifetime drinking or current drinking. In rural Maryland, 10th grade students who reported drinking on 1-2 days during the past month had higher risk of injury (types of intent unstated) than other students. ${ }^{10}$ Among 8 th graders, alcohol use in the past 30 days was a risk factor for injury in girls but not in boys. ${ }^{13}$ Another Maryland study reported that among students aged 11-17 in a rural county, alcohol users were more likely than non-users to have major or minor injury (types of intent unstated). ${ }^{15}$

Compared with binge drinking prevalence of $12.8 \%$ in youth aged 12-17 in our survey, the 1997 Iowa Youth Risk Behavior Survey found binge drinking rates of $28.7 \%$ in 9th graders, $37.6 \%$ in 10 th graders, $43.0 \%$ in 11 th graders, and $41.3 \%$ in 12 th graders. ${ }^{28}$ If our survey underestimated the 
prevalence of youth binge drinking, then we also underestimated the effect size of binge drinking on injury episode prevalence. The level of adult binge drinking in our study, $17.2 \%$, is very similar to the level estimated in 1995 in Iowa, $18.0 \%$, by the Behavioral Risk Factor Surveillance System. ${ }^{29}$

\section{Sports}

While the benefits of sports participation in children are important, ${ }^{30}$ it does pose risk of injury. In our survey, 39\% of injury episodes occurred in recreation or sport places, compared with $49 \%$ of all unintentional injuries in children aged 0-19 living on farms in five midwest states ${ }^{31}$ and 19\% of all primary care office visits for injury, of all intents, in US children age $0-18 .^{24}$

Although doubling the risk of injury related to team sports may be a modest increase, the prevalence of participation in sports in our survey, $70.6 \%$, is high. As shown by Rose in $1985,{ }^{32}$ a large number of people at a relatively small risk may give rise to more cases of disease than the small number who are at a high risk.

Our findings are consistent with previous research showing that in rural areas sport team membership is associated with an elevated risk of injury. ${ }^{10}{ }^{15}$ Regarding sex differences in sport related injury rates, the evidence is mixed, with some studies reporting higher injury rates in girls ${ }^{33}$ and others finding higher injury rates in boys. ${ }^{35}{ }^{34}$ None of these studies reported which types of intent were included in their injury case definitions, and none analyzed the rural children separately.

\section{Strengths and limitations}

This study sheds light on a special population-children in three different residential strata of a very rural area-and allows investigation of behavioral factors that are usually not available in injury studies. It uses a community sample and injury episodes of all causes, body parts, places of occurrence, and severities except death. Study questions asked directly and clearly about behavioral practices, and participants had no apparent motive to distort reports of injury or other variables. The possibility of bias was lessened by including the questions in a general health survey aimed at finding risk factors for injury and respiratory illness.

Because the survey response rate was low, the results should be interpreted with caution. Because parents were the reporting sources for these injuries, intentionality would often have been unknown. Our survey probably underrepresents the frequency of violent or intentional injuries. ${ }^{3}$ Because individuals are more likely to give socially desirable answers in face-to-face interviews than in telephone interviews, ${ }^{35}$ our results could be imprecise. However, few of the adults or children in the survey refused to answer the interview questions on a variety of sensitive topics. Injuries ascertained by interview appear to be underreported ${ }^{36-39}$ especially if the recall period is longer, if the injury is less severe, or if the injury is embarrassing. We did not use the injury narrative information to try to determine whether exposure to either sports or alcohol caused the injury.

\section{CONCLUSIONS}

Because the US lacks a continuous, incidence based nationwide surveillance system of non-fatal injuries with state and local data analysis capability, local studies such as ours can provide useful clues regarding the etiology of this still important public health problem. We were able to investigate some known and some new potential risk factors including behavioral aspects for childhood non-fatal injury in a very rural area. The cross sectional nature of our study limits causal interpretation of our findings of increased risk for binge drinking and sports participation. We plan to address this in future longitudinal follow up of this population.

\section{Key points}

- All-cause childhood injury prevalence seems to be higher in rural areas than urban areas.

- Children, especially girls, who play team sports or binge drink are more likely than other children to have an all-cause injury.

- Because team sports and binge drinking are popular among adolescents, the use of effective approaches to reduce these behaviors or modify their hazardous aspects may decrease all-cause injury rates.

\section{ACKNOWLEDGEMENTS}

This study was conducted with support from the National Institute for Occupational Safety and Health (U07 CCU 706145-05-1) and the National Center for Injury Prevention and Control (R49 CCR 703640 08), US Centers for Disease Control and Prevention. An earlier version of this report was presented in a poster session at the American College of Epidemiology Annual Meeting in Atlanta, Georgia, in September 2000

We thank Jeffrey J Sacks, MD, MPH of CDC for sharing the Injury Control and Risk Survey (ICARIS) questionnaire. Diana Jackson Sertterh, BA, interviewed the majority of study participants. We also thank Genna Moore, RRT, Beth Hoylman-Henning, RN, BSN, Ann Weenike Yeoman, RN, BSN, and Naomi Tucker for conducting additional interviews. Rohit Seem, MD, assigned ICD-9-CM codes to the injuries based on training and advice by Nancy O'Brien, RHIT. We thank Kevin M Kelly, PhD and Fang Qian, PhD for assistance with data management and analysis.

\section{Authors' affiliations}

D L Nordstrom, C Zwerling, A M Stromquist, J A Merchant, Department of Occupational and Environmental Health, University of lowa College of Public Health, lowa City, lowa

L F Burmeister, Department of Biostatistics, University of lowa College of Public Health, lowa City, lowa

\section{REFERENCES}

1 Baker SP, Fingerhut LA, Higgins L, et al. Injury to children and teenagers state-by-state mortality facts. Baltimore, MD: Johns Hopkins Center for Injury Research and Policy, 1996: 14

2 Institute of Medicine, Committee on Injury Prevention and Control. Reducing the burden of injury: advancing prevention and treatment. Washington, DC: National Academy Press, 1999: 42-43, fig 2.1.

3 Scheidt PC, Harel Y, Trumble AC, et al. The epidemiology of nonfatal injuries among US children and youth. Am J Public Health 1995;85:932-8.

4 Warner M, Barnes PM, Fingerhut LA. Injury and poisoning episodes and conditions: National Health Interview Survey 1997. Vital and Health Statistics 2000; 10(202).

5 Centers for Disease Control and Prevention. National estimates of nonfatal injuries treated in hospital emergency departments - United States, 2000. MMWR Morb Mortal Wkly Rep 2001;50(17):340-6.

6 Merchant JA, Stromquist AM, Kelly KM, et al. Chronic disease and injury in an agricultural county: The Keokuk County Rural Health Cohort Study. J Rural Health 2002;18:521-35.

7 United States Department of Agriculture. Rural-urban continuum codes (1998). Available at: http://www.ers.usda.gov/briefing/rural/ codes/RUCC. HTM (accessed 12 September 2000).

8 Overpeck MD, Jones DH, Trumble AC, et al. Socioeconomic and racial/ethnic factors affecting non-fatal medically attended injury rates in US children. Inj Prev 1997;3:272-6.

9 Fingerhut LA Warner M. Injury chartbook. Health United States 1996-97. DHHS No (PHS) 97-1232-1. Hyattsville, MD: National Center for Health Statistics, 1997.

10 Alexander CS, Ensminger ME, Somerfield MR, et al. Behavioral risk factors for injury among rural adolescents. Am J Epidemiol 1992;136:673-85

11 Bijur PE, Kurzon M, Overpeck MD, et al. Parental alcohol use, problem drinking, and children's injuries. JAMA 1992;267:3166-71.

12 Peterson L, Brown D. Integrating child injury and abuse-neglect research: common histories, etiologies, and solutions. Psychol Bull 1994; 116:293-315.

13 Alexander CS, Somerfield MR, Ensminger ME, et al. Gender differences in injuries among rural youth. Inj Prev 1995;1:15-20.

14 Rivara FP. Developmental and behavioral issues in childhood injury prevention. J Dev Behav Pediatr 1995;16:362-70.

15 Riley AW, Harris SK, Ensminger ME, et al. Behavior and injury in urban and rural adolescents. Inj Prev 1996;2:266-73. 
16 Ewing JA. Detecting alcoholism. The CAGE questionnaire. JAMA 1984;252:1905-7.

17 Buchsbaum DG, Buchanan RG, Centor RM, et al. Screening for alcohol abuse using CAGE scores and likelihood ratios. Ann Intern Med $1991 ; 115: 774-7$

18 Kessler RC, McGonagle KA, Zhao S, et al. Lifetime and 12-month prevalence of DSM-III-R psychiatric disorders in the United States. Results from the National Comorbidity Survey. Arch Gen Psychiatry 1994;51:8-19.

19 Kohout FJ, Berkman LF, Evans DA, et al. Two shorter forms of the CES-D depression symptoms index. J Aging Health 1993;5:179-93.

20 Radloff LS. The CES-D scale: a self-report depression scale for research in the general population. Appl Psychol Meas 1977;1:385-401.

21 Sayetta RB, Johnson DP. Basic data on depressive symptomatology, United States, 1974-75. Vital Health and Statistics 1980;11(216).

22 Centers for Disease Control and Prevention. Recommended framework for presenting injury mortality data. MMWR Morb Mortal Wkly Rep 1997;46(No RR-14): 1-30.

23 Collins JG. Types of injuries by selected characteristics: United States, 1985-87. Vital Health and Statistics 1990;10(175).

24 Hambidge SJ, Davidson AJ, Gonzales R, et al. Epidemiology of pediatric injury-related primary care office visits in the United States. Pediatrics 2002; 109:559-65

25 National Committee for Injury Prevention and Control. Injury prevention: meeting the challenge. Am J Prev Med 1989;5(3 suppl): 119

26 Smith GS, Branas CC, Miller TR. Fatal nontraffic injuries involving alcohol: a metaanalysis. Ann Emerg Med 1999;33:659-68.

27 Christoffel T, Gallagher SS. Injury prevention and public health: practical knowledge, skills, and strategies. Gaithersburg, MD: Aspen Publishers, 1999: 74
28 Centers for Disease Control and Prevention. 1997 lowa Youth Risk Behavior Surveillance System. Available at: http://apps.nccd.cdc.gov/ YRBSS/GraphV asp (accessed 30 January 2003)

29 Powell-Griner E, Anderson JE, Murphy W. State-and sex-specific prevalence of selected characteristics-behavioral risk factor surveillance system, 1994 and 1995. MMWR CDC Surveill Summ 1997;46:1-31.

30 Weaver NL, Marshall SW, Miller MD. Preventing sports injuries: opportunities for intervention in youth athletics. Patient Education and Counseling 2002:46:199-204.

31 Gerberich SG, Gibson RW, French LR, et al. Injuries among children and youth in farm households: regional rural injury study-I. Inj Prev 2001;7:117-22.

32 Rose G. Sick individuals and sick populations. Int J Epidemiol 1985;14:32-8

33 Powell JW, Barber-Foss KD. Sex-related injury patterns among selected high school sports. Am J Sports Med 2000;28:385-91.

34 Lenaway DD, Ambler AG, Beaudoin DE. The epidemiology of school-related injuries: new perspectives. Am J Prev Med 1992;8:193-8.

35 Armstrong BK, White E, Saracci R. Principles of exposure measurement in epidemiology. New York, NY: Oxford University Press, 1992: 37-9.

36 Braun BL, Gerberich SG, Sidney S. Injury events: utility of self report in retrospective identification in the USA. J Epidemiol Community Health 1994; 48:604-5

37 Harel $Y$, Overpeck MD, Jones $\mathrm{DH}$, et al. The effects of recall on estimating annual nonfatal injury rates for children and adolescents. Am J Public Healh 1994:84:599-605.

38 Landen DD, Hendricks S. Effect of recall on reporting of at-work injuries. Public Health Rep 1995;110:350-4.

39 Zwerling C, Sprince NL, Wallace RB, et al. Effect of recall period on the reporting of occupational injuries among older workers in the health and retirement study. Am J Ind Med 1995;28:583-90.

\section{LACUNAE}

\section{Squirrels and jaywalking}

o one ever said a squirrel's life was easy. Just how tough it may be for male squirrels, however, has been found by a study at Texas A\&M University. A Department of Wildlife and Fisheries Sciences Animal Ecology course student project that tracked radiocollared fox squirrels on campus found that one quarter of the males did not survive the first year. But is wasn't hunger or predators that killed them. They were all run over by cars. Fewer females died, with most killed by predators (reported in the New York Times, May 2003; submitted by Peter Jacobsen, who notes that many injury prevention folks may wonder about the sex difference in unintentional injury; this study, he points out, indicates a biological explanation and that the New York Times headline blames the victim!).

\section{Crocodile teeth a health hazard!}

ustralian scientists have found that crocodile teeth are a health hazard! Scientists from Darwin have

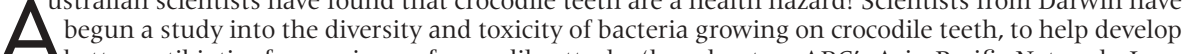
better antibiotics for survivors of crocodile attacks (broadcast on ABC's Asia-Pacific Network, June 2003; submitted by Ian Scott). 